\title{
RPTRA CONCEPT IN THE ARCHIPELAGO: BASED ON AN EQUALITY AND LEGAL PROTECTION APPROACH
}

\author{
Yophie Septiady $^{1}$ and Aartje Tehupelory ${ }^{2}$ \\ Master of Architecture Department, Universitas Kristen Indonesia, Indonesia \\ ${ }^{2}$ Doctor of Law Department, Universitas Kristen Indonesia, Indonesia
}
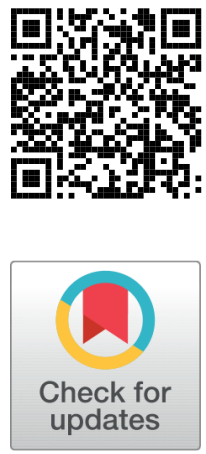

Received 8 July 2021

Accepted 19 July 2021

Published 31 July 2021

Corresponding Author

Yophie Septiady, yophie1971@gm ail.com

DOI $10.29121 /$

granthaalayah.v9.i7.2021.4105

Funding: This research received no specific grant from any funding agency in the public, commercial, or not-for-profit sectors.

Copyright: (C) 2021 The Author(s). This is an open access article distributed under the terms of the Creative Commons Attribution License, which permits unrestricted use, distribution, and reproduction in any medium, provided the original author and source are credited.

\section{ABSTRACT}

The focus of the discussion in this study is on the design and needs of RPTRA in communities with different environmental and cultural contexts. Including the understanding of the surrounding community who "get" the RPTRA regarding the procedures for its use and maintenance. An equally important part is the concept of "child-friendly", what kind of understanding and implementation is there, and its legal basis (particularly for the protection of children in public spaces - RPTRA). This research was conducted on Tidung Island, one of the islands in the South Thousand Islands District, Seribu Islands Regency, DKI Jakarta Province. Several things that need to be considered as a reference in the development of RPTRA in archipelagic areas based on an architectural approach: (1) Access and affordability, (2) Community involvement in RPTRA design, (3) RPTRA which also basically pays attention to children with special needs, (4) Maintaining Green Open Space compared to the existence of buildings, (5) Prioritizing activity facilities that are the choice of the surrounding community, (6) RPTRA design must pay attention to weather conditions in coastal areas, (7) Socialization to the surrounding community on the character of materials and their use, (8) RPTRA designer's understanding of zoning and facility classification, (9) Setting zoning activities between toddlers and youth, (10) Utilizing existing facilities outside the RPTRA. Several things that need to be considered as a reference in the development of RPTRA in archipelagic areas based on a legal approach are: (1) The legal aspects of establishing an RPTRA based on the ideal area, (2) The conception of RPTRA as accommodating the idea of a child-friendly city based on existing regulations, (3) Legal studies to harmonize RPTRA with the PKK Main Program based on Governor Regulation Number 40 of 2016 have not gone well, (4) Legally (based on Governor's Decree Number 349 of 2015 concerning the Implementation Team for RPTRA Development and Maintenance) the role of RPTRA managers must also be emphasized its main tasks and functions. 


\section{INTRODUCTION}

Childhood is a time of fond memories associated with play activities. Talking about how children play today - in the era of modernization - will never end, especially urban children's games. Playing with children using gadget media such as cellphones or computers has become a decoration material for discussions and seminars that have been rampant in the last ten years. The mindset of parents that children are safer and more comfortable playing in the house that existed around the 1980s; now it has turned into concern because children are constantly at home because of "addiction" to gadgets. This problem finally gave rise to the encouragement of parents (in general) that children "must" play outside the home - move their bodies, get to know their environment, interact and socialize directly (face-to-face) with their friends; and not interacting with gadgets.

Parents' concerns regarding the need for socialization and interaction and a play space for their children were responded to directly by the DKI Jakarta Provincial Government. The DKI Jakarta Provincial Government has built 188 child-friendly integrated public spaces (RPTRA ${ }^{1}$ ) during the leadership of Governor Basuki Cahya Purnama Suraya et al. (2019). From other data from the DKI ${ }^{2}$ Jakarta Child Protection and Population Control Empowerment Service, the number of RPTRAs that have been built since 2015-2016 is 186. The $\mathrm{APBD}^{3}$ was from Corporate Social Responsibility (CSR) of private companies.

In addition, it is hoped that RPTRA will be present during the community because of the disappearance of children's play spaces and places for exercise for the public in open land, which due to the construction of buildings, housing, and settlements, has become a problem for the unbalanced development of the City of Jakarta Prakoso and Dewi (2018). The need for this RPTRA also exists in children and communities in islands, such as the Thousand Islands, DKI Jakarta. They also need open space and interaction like children who live in big cities. Moreover, several islands in the Thousand Islands are already inhabited and relatively densely populated at this time.

According to Saut Marbun, Head of the Development Section of the Thousand Islands Public Housing and Settlement Sub-Department, (in Media Indonesia, 27 February 2017), in 2017, there were 5 RPTRAs built in the Thousand Islands with DKI Jakarta APBD funds. The five RPTRAs will be built with a fund of Rp. 8 billion. The locations are: South Thousand Island District Park, Tidung Island, RW ${ }^{4} 02$ Harapan Island, RW 04 Kelapa Island, RW 03 Panggang Island, and RW 03 Lancang Island. Furthermore, Saut Marbun explained that the RPTRA facility has several playgrounds for children, such as volleyball or basketball courts. In a different place, the Governor of DKI Jakarta at that time, Basuki Tjahaja Purnama, said that the number of RPTRAs in the Thousand Islands was still minimal and far from the expectations

\footnotetext{
${ }^{1}$ RPTRA stands for Ruang Publik Terpadu Ramah Anak

${ }^{2}$ DKI stands for Daerah Khusus Ibu Kota Jakarta

${ }^{3}$ APBD stands for Anggaran Pendapatan dan Belanja Daerah

${ }^{4} \mathrm{RW}$ stands for Rukun Warga
} 
problem numbers. Ideally, one RW has one RPTRA.

RPTRA is the concept of public space in the form of green open spaces or parks equipped with various exciting games, CCTV monitors, and rooms that serve the interests of the community around the RPTRA, such as library room, $\mathrm{PKK}^{5}$ Mart, lactation room, and others Hermawati and Muchbarak (2020). It was further informed that in 2018 the provincial government. DKI Jakarta has established as many as 290 RPTRAs in each kelurahan. Further information that until March 2019, there had been 296 RPTRAs that the provincial government had inaugurated. DKI Jakarta. Based on data obtained from the Office of Empowerment for Child Protection and Population Control of DKI Jakarta, the areas with the highest number of RPTRAs are in East Jakarta Administrative City and North Jakarta Administrative City 64 units of RPTRA. A total of 228 RPTRA units in DKI Jakarta were built at the expense of the DKI Jakarta APBD, and 68 RPTRA units were built with CSR financing.

The focus of the discussion in this research plan is on the design and needs of the RPTRA in communities with different environmental and cultural contexts. Including the understanding of the surrounding community who "get" the RPTRA regarding the procedures for its use and maintenance Rustanto and Akhmad (2021). An equally important part is the concept of "child-friendly", what kind of understanding and implementation it is, as well as its legal basis Chan et al. (2016). Therefore, the research team of lecturers will collaborate between the lecturers of the Master of Architecture Program and the Postgraduate Program of the Faculty of Law of the Christian University of Indonesia to obtain an ideal picture that is expected to be a benchmark for the development of a contextual RPTRA that has the concept of equality and legal protection for children in Indonesia. Public spaces, especially RPTRA located in island locations/territories.

In one context, users of architectural works have one primary identity and several other identities tailored to their interests, including users' interests in line with the fulfilment of some of their needs. These needs arise because of choices both inside and outside the original culture Torabi and Brahman (2013); Tschersich et al. (2011). However, these choices rarely "directly" replace the values that exist in the original culture. A society may have an architectural work with a modern style because of its financial capital and identity from its social network, but the original culture is an essential principle that is the fundamental identity of the building it owns Brown et al. (2010). This fundamental identity can be observed based on behavioural patterns that arise from how actors use and interpret each form and space in the building.

Through the above explanation, in matters related to the RPTRA construction, the task of an architect before the building is to identify the original culture of his client because that is his fundamental identity Erul (2018); Permanasari et al. (2019). Once identified, make particular observations on the context in which the RPTRA stands - whether it can "accommodate" or even clash with the client's original culture. What deserves further analysis is the trend of development from the context of

\footnotetext{
${ }^{5}$ PKK stands for Pembinaan Kesejahteraan Keluarga
} 
development progress. Pay attention to the possibility that the work can still represent the conditions of its environment. The following phased analysis examines the possibility of changing lifestyles, and user needs in line with the social and economic changes Haenfler et al. (2012).

All development programs related to the existence of local governments are motivated by (a) services that are closer to the community than those who are served and (b) the desire to create community welfare democratically "Decentralization And Local Governance In Developing Countries: A Comparative Perspective" (2006). To achieve this, the Provincial Government of DKI Jakarta should consider the native point of view in designing a physical development policy apart from infrastructure development. Their environment must guide developments that function as public spaces for people to interact and socialize: environmental advantages and disadvantages Grusec (2011). Weather factors, which also involve the scorching sun and vegetation in the environment, will more or less affect the arrangement of the space openings. Sarah and the strength of the wind will affect the shape, height and surface of the design. If we study from the side of the use of space socially, it will affect the behaviour of its users in public spaces.

The various points of view that become the research problem above can be mapped based on the types and classifications. Each type is likely to affect the other types; so are the classifications - one class will affect the other. It also does not rule out the possibility that the types will be related to the existing classifications. Therefore, to "answer" this research problem, fundamental data from the field are needed to find the types and classifications. If the types and classifications have been obtained, then a stage is made in building the RPTRA. Three formulaic steps become the stages in building RPTRA in the archipelago: understanding the essential capital of a design, studying the social capital of a design, and determining the ideal capital of a design. The objectives of this study are a) Produce a formulation of approaches in designing public spaces (in this case RPTRA) for islands or regions - or other particular areas and b) With the above objectives, it is expected to create a thematic and appropriate public space, with the purpose of planning and the character of the community.

\section{LITERATURE REVIEW}

The actualization process develops or discovers the identity and the blooming of existing or hidden potential Richards (2007). Self-actualizing people are more assertive and have a clearer understanding of right and wrong. Have a humble nature, listen to others patiently, be willing to admit that they do not know everything and that others will be able to teach them something - that happiness is part of achieving happiness. They are full of confidence and have self-respect. The self-actualizing person has a pleasant personality and sees the world in a more unified way. For example, Maslow proved that children need acceptance, protection, 
affection, and appreciation psychologically, but they depend entirely on their capacities Maslow (2019). The basic concept of self-actualization that will be raised in the RPTRA design is expected to lead to social interactions that are "reciprocal interests". What is meant by reciprocal attraction is that if someone else's behaviour towards himself is interpreted as positive towards himself, he will feel that he has benefited and reciprocate the other person's interest against him Pai and Tsai (2016). The aim is to find a balance in which social interaction occurs in its context (in this case, RPTRA).

RPTRA and human behaviour in public spaces - The "spatialization" of everyday behaviour examines how sociospatial is translated into physical experience and practice. Faedlulloh and Prasetyani (2017) He proposed the central concept of habitus, a generative and structural principle of collective strategies and social practices used to reproduce existing structures. Unlike previous theorists, Bourdieu also examines the effects of feedback on the social system. The notion of "spatialization" is about space and spatialize (locating) human experience more effectively in cultural anthropology. Spatialize means to place, both physically and conceptually, social relations and social practices in social space. Complementary perspectives of the production of social space and the construction of social space help us understand how public spaces in urban society become semiotic signs and interpret reality Håndlykken-Luz (2019).

Influential theories of human spatialization and cultural anthropology and human experience must integrate perspectives on social production and social construction of space, both of which contextually emphasize the forces that generate and represent people as social agents who construct their meanings and realities. Nevertheless, it must also reflect these two perspectives in the experiences and daily lives of users of social space Fergie et al. (2016). The meaning built based on the perpetrator's reality is conveyed through messages through various communication media that can affect the community. These effects or impacts can be classified into 3 , namely cognitive effects, affective effects and behavioural effects. The cognitive impact arises in the communicant that causes him to know and increase his intellect. The affective impact is an impact that is not only so that the communicant knows, but the communicant is moved, causing certain feelings. Behavioural impacts impact the communicant in behaviour, actions, or activities Cao (2010); Partington and Cushion (2013). This effect is expected to appear in the idea of RPTRA.

RPTRA and the culture of the archipelagic community - The presence of RPTRA is part of the socialization process between communities in the public sphere. In this case, socialization is closely related to cultural learning. Socialization is a social process that a person lives through or a lifelong process that an individual needs to become a group member and society through cultural learning from the group and society Jarvis (2011). The socialization process starts when the individual is born into a family to learn and accept the values, attitudes, skills and roles that can shape his personality and unite himself into the group and society. 
Thus, the family in all societies is the agent of socialization for their children, and the process experienced by the individual is called primary socialization, which usually has emotional and affective characteristics. In the process of becoming an adult, a person carries out various activities, including school, peer groups, members of sports clubs, all of which are now agents of socialization for individuals in learning their new roles, called secondary socialization Baslington (2008). The socialization that took place in the RPTRA, referring to the explanation above, was included in the secondary socialization.

RPTRA is one of the public spaces. The definition of "public" in the study context is defined as a set of norms that support creating a public order. The public functions to regulate the ways (regulate) face-to-face interactions and other forms of social relations that do not require direct contact. This definition of public order is always tied to the context in which it occurs, namely within the public spaces themselves - in this case, the public space of the archipelago. Thus, the notion of public order must be related to the notion of public places as territorial spaces in a community that are freely accessible to members of the community itself Goffman (2017).

RPTRA in architectural design concept - The expected result of good public space development is forming communities in society. The same is the case with the creation of RPTRA (Child-Friendly Integrated Public Spaces) throughout the capital city of Jakarta. If the initial concept of RPTRA was built only to provide playing facilities for children in the surrounding environment, then the RPTRA is nothing more than a satisfying entertainment entity for individual children. If so, the essence of play - interaction and socialization between individuals - is not achieved. There is no change in the identity of the citizens from the community that will remain a community, where they do not know each other and are anomie.

Interaction and socialization are not like gathering people and seeing other people. If so, RPTRA is not like a crowd of people who have no connection at all. The feeling of togetherness between individuals should be built since childhood (children). RPTRA is one of the forums that can build this goal. Therefore, in building the RPTRA, it is better to pay attention to the Social Capital of a Design and the Idea Capital of a Design, including visual accuracy, information and certainty of feelings and complementary needs. Society is a unit of social life in which its members may not know each other. Bound by a unit of social life through its institutions. Occupy areas with clear boundaries. They had a culture that is different from the culture of other communities. Community members live from utilizing the resources that exist in their environment. Its members have an attachment to its territory and make their territory a reference for their identity in dealing with other communities. The community is a collection of individuals who live together based on the culture they have in common. A community can be seen as a small-scale unit of life that occupies an area Katz and Lyerly (1963). Communities can also be seen as associations of professions, interests or others. Community cultural rights are intended to include these two meanings but are primarily aimed at understanding the community as a unit of 
life Wang (2013).

Regarding the differences between society and community, it can be understood that the concept of community brings more citizens (cities) to be more concerned about development facilities and the environment around their lives. Architectural planning strategies are needed. The goal is that the spatial patterns in the RPTRA are formed following the interaction and communication from its citizens' expectations, not the benefi

ciaries' hope.

Suppose the RPTRA is reviewed based on the accuracy of the design and the area of space. As a matter of thought, is it true that RPTRA is indeed a "child-friendly" space? Then what is carried by the first party with the concept of "child-friendly"? Does providing children's games that tend to be individual (swings, slides, single seesaws) meet the child-friendly criteria? In my opinion - without reducing respect to the first party for all their efforts - the formation of the RPTRA has not been careful and has not fulfilled the child-friendly element.

Regarding the friendliness and safety of children in the RPTRA, it is necessary to ask questions, because in general, the location of the children's play facilities is quite far from the sports facilities for adults. Sports facilities for today generally use assistive devices that can endanger the safety of children, such as the use of a ball that must be kicked firmly (futsal), hit hard (volley), and thrown firmly (basketball) - all of which can be dangerous if about children playing in their place. It is where the dramaturgy problem occurs. Will the children step away from the stage when teenagers and adults want to exercise around them? Thinking about the form of space and its arrangement is fundamental to be realized in architecture.

\section{RESEARCH METHOD}

This research will use a qualitative approach. The definition of a qualitative approach is an approach that focuses its attention on the general principles that underlie the manifestation of the units of symptoms that exist in human life or their patterns. The qualitative approach is about multi-methodology Ferrara and Friant (2016). Qualitative research as an interpretive tool for social phenomena does not give privileges to one methodology over another. Qualitative research models are used in many disciplines separately; the approach does not have a specific set of entirely own methods. The technique uses observation and in-depth interviews, and data on the researcher's experience while at the research site Guest et al. (2013); Ritchie et al. (2013). The observations that will be carried out are more passive observations, where we do not make direct contact with the research subjects but only observe the patterns made by the actors in a particular context, namely in the RPTRA room. The passive observation was carried out so that our presence would not be felt to distract or interfere with the activities of residents in the RPTRA environment. Indepth interviews are carried out if there are exciting things regarding the focus and 
scope of the research design that you want to explore more deeply. The technique is by looking at the condition of the research subject when conducting interviews. Do not feel rishi and pressured by the questions asked. Therefore, the questions will be adjusted to the age level, education level, and condition of the research subject at that time (alone or with other people). The experience of researchers when they are at the research location is needed to determine the accuracy, safety, and comfort of the RPTRA tools and conditions in the archipelago.

How is the influence of sunlight and natural vegetation, the direction and strength of the wind, the shape of the pavement surface or soil. This research uses a case study approach, which we consider appropriate in answering the problems in this study because a) It is used for qualitative research specific, specific, and local in scale; b) Case studies are widely used in research in the field policymaking. A case study is an approach to study, explain, or interpret a case in its natural context without any intervention from outsiders. The case study tries to highlight a decision - in this case, the construction of the RPTRA on Tidung Island - why the decision was taken, how it was implemented, how it came out. After that, a formula was found to build a contextual RPTRA following the archipelago. As stated in the final results of the case study, namely the nature of the case itself and the physical setting, the context of the case is mainly in the aesthetic, social, and legal fields Stake (2013). This research was conducted on Tidung Island, one of the islands in the South Thousand Islands District, Seribu Islands Regency, DKI Jakarta Province. Regarding the context, this research covers 2 islands, namely: Pulau Tidung Besar and Pulau Tidung Kecil.

\section{RESULT AND DISCUSSION}

One program that pushed for developing cities in Indonesia to accommodate children's rights is child-friendly cities. In Indonesia, this idea began to develop in 2006 and was legitimized by the PPPA Ministerial Regulation Number 2 of 2009 concerning the child-friendly cities Policy, where this program was piloted in 10 districts/cities. RPTRA is one form of the child-friendly cities program. For the Tidung Ceria RPTRA on Tidung Island, there are several important factors to be analyzed, including:

Access and Affordability: Site Selection - Based on the reality on the ground, Tidung Island RPTRA is needed by Tidung Island residents. His presence in 2017 has been awaited by every level of society that needs public space on Tidung Island. It is due to the condition of settlements on Tidung Island which looks dense and dense. There is almost no land left in the settlements that the community can use to interact and socialize.

The condition of Tidung Island, which is densely filled with residential land, makes

the Regional Government on Tidung Island have difficulty in determining the land for the establishment of the RPTRA. According to Mrs Hafsah, "It is difficult to build an RPTRA based on the standard area determined on Tidung Island because there are already many settlements and lodging for tourism". With various considerations 
(see: History of the Tidung Island RPTRA), finally, the establishment of the RPTRA was placed in front of or opposite the South Thousand Islands District Office.

Regarding this location, it is acceptable for teenagers and parents to reach it; however, this is not the case for children because the location of the RPTRA is quite far from the settlements of residents living around the village office. Not to mention the safety issue of children who have to walk on the busy axle road with two-wheeled motorcycles and bicycles. The width of the road, which is only about 2 meters, makes road users have to share by prioritizing vigilance and patience.

Some children who find it difficult to reach the RPTRA can only play in the Pulau Tidung Village Office (near the pier) with the above conditions. The existence of a shallow pond to keep ornamental fish is also an attraction for children. In addition, the kelurahan office yard, which is always clean, makes the children feel comfortable playing. The large shady trees provide shelter for children to play in the sun.

The children can play in the park, which is located right across from the village office. Nevertheless, they did not do that because the condition of the park was outdated. The condition of this park is not the community's choice to use it because, since the existence of the RPTRA, the prestige of the park does not shine anymore, even though the atmosphere is fantastic because several shady trees protect it. Previously some residents or guests travelled to take advantage of the existence of the park. Suitable for just sitting or for children's play area. However, it looks desolate right now, and there is not a single person taking advantage of it.

Mrs Hafsah revealed that she was concerned about a park in front of the subdistrict office, which seemed unmaintained. As a village head, he plans to beautify the park, but it is difficult to get funds for its implementation because the current budget allocation is prioritized for handling COVID-19; In addition, there is an RPTRA with a predetermined budget, both for maintenance and program activities. According to Mrs Hafsah, one way to "revive" the park is with CSR funds, but the planning must be clear and transparent so that potential donors are sure of the benefits of developing the park.

This park was created to provide a means of play and entertainment for children. As Hafsah's mother said, "This park was made to make children happy. There is a mini swimming pool equipped with a big bucket to splash the children under, just like in Ancol, even though it is 'far'... haha haha." The first time the mini swimming pool was operated, the children were delighted, but now it is just a memory. The prestige of the mini pool is inferior to the existing facilities in the RPTRA. It can be seen that the swimming pool is no longer filled with water, and the condition seems to be unkempt, dirty and filled with dry leaves falling from the trees above.

Community Involvement in RPTRA Design - Based on Governor Regulation Number 196 of 2015 concerning Guidelines for RPTRA Management, which was updated by Governor Regulation Number 40 of 2016 concerning Guidelines for RPTRA Management which contains directions regarding positions, duties and functions; services and activities; ban; organizing; work partners; division of tasks for handling 
infrastructure and facilities. The explanation explains that the RPTRA was built to a) Provide open space for the fulfilment of children's rights so that children can live, grow, develop, and participate optimally following human dignity; b) Providing infrastructure and facilities for partnership between local government and the community in fulfilling children's rights; c) Providing city infrastructure and facilities as a Child-Friendly City; d) Provide infrastructure and facilities for the implementation of the activities of the 10 PKK Main Programs; e) Increasing the achievement of green open spaces and groundwater absorption areas; and f) Improving the infrastructure and facilities for community social activities including the development of knowledge and skills of PKK cadres.

The paragraph above in point 2 has not fully appeared in the RPTRA-both from planning, development to management. Regarding spatial and architectural planning, the community of potential RPTRA users is not involved - especially parents and their children. The habits, needs, desires, and expectations of children about play are for them. As we know, architectural work is to create a space that can accommodate human activities (the owner/user of the space), which in its design is adjusted to the users' goals, needs, and social and cultural behaviour.

RPTRA, which also pays attention to children with special needs (disabled), has not been seen in the development of RPTRA on Tidung Island. Design of steep pedestrian paths when moving to dirt tracks, constructing facilities for children with special needs, such as holding aids for blind children and children who have limited walking due to disability in their feet. What we see is that in terms of design, the RPTRA tends not to involve the community in its design and has not paid attention to the interests of children with special needs.

Therefore, in designing the RPTRA, which is part of the development carried out to benefit the general public, creative ideas from architects must emerge by exploring community involvement, resulting in a mapping of existing potentials and problems.

Construction of the Tidung Ceria RPTRA in terms of inter-space relations - After the RPTRA is built, some open land will generally accommodate specific activities for children's activities and PKK activities. Because children's play facilities are available, the use of open land is more focused on activities related to PKK, such as planting several types of trees that function as food crops (cassava, sweet potato, pakchoy, mustard greens, spinach, kangkung) or medicinal plants.

Problems arise in using this open land to become a Toga Park, namely the community's involvement in determining the types of plants, providing seeds, planting, maintaining, and utilizing the results. All this was thoroughly carried out by 6 PPAPP Sub-department officers (Empowerment, Child Protection, and Population Control) who came from the community around the location. Almost none of the local communities or PKK groups were involved. PJLP members usually do all the work starting from the instructions of the RPTRA manager, but occasionally there is also input from the lurah and his staff. According to Dodi Pratama (20 years old, a member of the PJLP), although the community does not participate in planting, they are allowed 
to use the results of the Toga Park. It was conveyed in response to the notion of community involvement.

The impact of this activity in the study of architecture is to make spatial relations inconsistent and well conceptualized. For example, in our research, the RPTRA on Tidung Island: the front or main entrance is directly opposite the South Thousand Islands District Office. Because the condition of the road in front of the main entrance is not too wide, which is about 3 meters, RPTRA users who come by motorbike prefer to enter from the back door. So, the main door is rarely used. The main gate was not chosen for people who use motorbikes, also because they were worried that it would disrupt the circulation of people going in and out of the sub-district office. Especially if their motorbikes are parked in front of the main entrance. Alternatively, even, previously the kelurahan had recommended that residents who came by motorbikes park their vehicles at the back door of the RPTRA.

Toga Park, which is at the back door, is planted with tubers (cassava). Besides being visually and aesthetically unattractive when visitors enter the RPTRA, it will also pollute the surrounding pedestrian paths because planting and caring for cassava plants is different from planting and caring for ornamental plants. Plants with pots are placed like they are not well planned. It interferes with pedestrian circulation. Not to mention if PJLP officers' water the plants, the pedestrian path becomes wet and slippery. This condition is bothersome for pedestrians, especially children and people with disabilities.

Another architectural problem is the construction of a massive brick wall along the back of the RPTRA. So, the part that uses a see-through iron fence is only on the face of the RPTRA, and even then, it is not complete. It means the people visuals (in and outside) of the RPTRA will be hampered because a massive wall covers it. It also affects the air circulation entering and leaving the RPTRA.

What is even more unfortunate about the wall construction is that it closes the beautiful view from inside the RPTRA towards the beach. Whereas around the beach outside RPTRA, several seats have been made for residents who want to enjoy the beach beauty. Not only the beach was jutting into the sea edge, but a stage has also been built as a place for local people to gather and display creativity. However, its manufacture does not consider the strong sea breeze, so it will be challenging to perform arts and cultural performances on the stage due to wind disturbances. In our opinion, constructing a stage on the beach is very good, but it is necessary to pay attention to wind gusts and safe electricity in its design. In addition, the stage should also be an integrated part of the RPTRA, as part of the purpose of making the RPTRA - not separate or stand-alone even though they are close together.

Use of Green Open Space for Buildings in the RPTRA - Green open space, which is becoming increasingly critical in Jakarta - as water catchment - apparently is not maintained in the construction of the RPTRA. The Green City concept, which has often been touted at seminars in Jakarta capital city, is like the whisper of the wind that passes from the ears of policymakers. There have been criticisms that have occurred 
in the construction of the RPTRA, especially on hardening some green open land with concrete. Not to mention the existence of multi-purpose buildings, which are pretty significant, approaching 1:4 land area, especially for RPTRA on Tidung Island.

In addition, the construction of public facilities in the RPTRA also does not prioritize the problem of water catchment areas, especially in the construction of basketball, futsal and amphitheatre fields that are full of concrete. These three facilities are like a "must" in the construction of the RPTRA because, from the outset, it was stated that the RPTRA design in DKI Jakarta Province is typical - including the facilities. Another problem that needs to be asked is whether the community needs the two facilities?

Based on the observations of the RPTRA on Tidung Island, within a few days to the RPTRA location from 2 visits to Tidung Island, the amphitheatre is always deserted, and none of the residents (adults, teenagers, or children) takes advantage of this facility; not even to sit there. This condition occurs because the design does not consider the weather conditions of the coastal areas or islands that tend to be hot/hot. A seat made of concrete tends to store or retain heat due to sunlight falling on the surface. Let alone sitting, just standing in the amphitheatre, is not comfortable because of the hot sun. Not to mention if there is a mighty beach wind. Of course, it is difficult for the children to take shelter from strong winds because the existing amphitheatre design does not take these factors into account.

In addition, specifically for the futsal field, it is indeed used by the community, especially by students or teenagers. Alternatively, it can even be said that this futsal field is "only for" students or teenagers. Then what about adulthood? Adults on Tidung Island are fond of volleyball. Volleyball fans are not only adult men or fathers but also mothers. Every afternoon they do volleyball in a small field along the Tidung Island axis road, close to the Cinta Bridge. Unfortunately, the people's passion for volleyball is not appreciated in the development of the RPTRA.

Volleyball courts do not require concrete pavement and the like, enough with a flat surface of soil or sand. In addition, a volleyball court with a beach sand bed makes it better to absorb rainwater that falls to the ground (unobstructed). Problems arise based on observations when mothers want to play volleyball far from the RPTRA while their children want to play in the RPTRA. The scene that happened was that mothers had to accompany/accompany their children first to play at the RPTRA, then they headed to the volleyball court - back and forth on motorbikes.

The distance is far enough for children and adolescents to go and use the RPTRA facilities, making them have to use motorized vehicles. Therefore, we can see many motorbikes that fill the back of the RPTRA for modest parking. In the afternoon, the motorbikes parked behind the RPTRA are usually used by teenagers. For male teenagers, their primary purpose at the RPTRA in the afternoon is specifically to play futsal. Meanwhile, they sit and chat with their friends for female teenagers, occasionally paying attention to their surroundings. 
RPTRA User's Understanding of Material Character and Its Use - Based on field observations, almost all RPTRA user communities on Tidung Island do not yet understand the character of the materials for making the existing facilities in the RPTRA, which is related to the use of these facilities. This misunderstanding is seen mainly in children's playgrounds, in the use of play floors. For example, in the Tebet Utara RPTRA, in the Tebet Timur Village, Tebet District, South Jakarta, children and parents at the children's playground will take off their footwear shoes and sandals. The reason is that, on average, they know they will keep floors made of synthetic materials clean. Meanwhile, at the Tidung Island RPTRA, it was seen that no one took off their footwear, neither the children nor the parents who accompanied them.

RPTRA Designer's Understanding of Zone Creation and Classification of Plant Zone and Play Zone Facilities (Children and Adolescents/Adults) - The placement or division of space zones based on activities and age levels has not been entirely accurate in the design Tidung Ceria RPTRA. The play zone for toddlers is placed adjacent to the futsal sports game zone. Even though they are provided with a safety wire fence, movements such as running, chasing, fighting feet until the futsal players fall to provide an unpleasant sight for toddlers, this reasonably challenging sport is not yet worthy of being aligned with the children's play zone. The problem with the futsal field zone is also the distance that is close to the amphitheatre. Whereas in the amphitheatre there is a place for children to play engklek. It is pretty dangerous if the ball from a futsal player hits a child standing on one leg when playing crank. Another problem is the distance between the basketball court and the fish rearing pond. Bla basketball is very likely to bounce and fall into the fish pond.

Legal Aspects of Establishing an RPTRA Based on Ideal Area - the ideal area to establish an RPTRA is $5,000 \mathrm{~m}^{2}$ Egaratri (2017). The goal is to make RPTRA more open. In other words, it is recommended that the ideal area of the RPTRA alone is to maintain open space, especially if the area is less than ideal. It is better to pave the floor for playing and sports facilities and reduce land use for buildings.

Tracing the Conception of RPTRA as an Accommodator of Child-Friendly City Ideas Based on Regulations - the emergence of RPTRA is one of them related to the concept of child-friendly cities Faraz et al. (2018). The following is a summary of excerpts from the statement in question: In Indonesia, the idea of a Child-Friendly City began to be developed in 2006 and began to be legitimized When the Minister of PPPA Regulation No. 2 of 2009 was issued regarding the Child-Friendly City Policy, where this program will be piloted in 10 districts/city. This idea arose because it was judged that children's rights were still not accommodated in development, and the high level of violence against children - both in the school environment, community, and family environment. In addition, another main focus that Child-Friendly City wants to fix is the problem of limited children's play space which should be able to increase children's creativity. It is inseparable from the high public demand for public spaces as a place for children to play in residential areas. 
The idea of child-friendly cities later became the basis for the DKI Jakarta Provincial Government in issuing regulations related to RPTRA. Precisely in 2015, the Provincial Government of DKI Jakarta issued Governor's Decree No. 349 of 2015 concerning the Implementation Team for the Development and Maintenance of RPTRA, which contains the target for achieving one RPTRA development in each kelurahan. Next, regarding the technical guidelines for RPTRA management, Governor Regulation Number 196 of 2015 was later changed to Governor Regulation Number 40 of 2016. Here RPTRA acts as a facility or public space provided by the DKI Jakarta Provincial Government to develop human beings.

The basis of the development of the RPTRA also refers to the Child Protection Act No. 23 of 2002 article 11, concerning the needs of children for playing spaces. However, the understanding of a play for children tends to be less realized in the development of RPTRA. The suitability of the RPTRA development to the context has not been appropriately implemented Yuniastuti and Hasibuan (2019). Different contexts - different patterns of life - different cultures - and different patterns of play for children have not been reflected in the development of a typical RPTRA. Children who usually play in the islands or the beach are likened to the design of the RPTRA with children who usually play in urban areas. It is an essential concern because it increases children's awareness and concern for the surrounding environment.

The existence of RPTRA aims to realize the child-friendly cities program, which is motivated by the rise of various cases of children, including violence, neglect F. Arlinkasari (2021). However, as a public space, the existence of RPTRA is intended for children and various ages. RPTRA has also functioned as a form of implementation of 10 main programs for Empowering Family Welfare (PKK) which accommodates the needs of families, ranging from toddlers to the elderly Arlinkasari et al. (2020).

Based on the quote above and the results of field investigations (incredibly the "Tidung Ceria" RPTRA on Tidung Island), efforts to realize child-friendly cities through the RPTRA program have become unfocused the PKK Main Program must accompany them. However, in this study, we can deepen "the bond between RPTRA and the PKK Main Program". In the "Tidung Ceria" RPTRA, activities involving play and creativity for children do not coexist or go hand in hand with the activities of the PKK Main Program. So, children play in their "own space", and the PKK Main Program activities are in their own space. The expected synergy has not yet been formed. In this case, the legal study to harmonize the RPTRA with the PKK Main Program based on Governor Regulation Number 40 of 2016 did not go well; and this is also possible in most of the RPTRAs in DKI Jakarta.

For example, planting cassava trees based on the PKK Main Program, number (3) on food does not involve children. Whereas if it refers to sections (6) and (9) of the PKK Main Program, the activities can involve children for Education and skills and Environmental Sustainability which can be taught, trained, tried/done to children to increase their knowledge of how to work together planting and preserving the 
surrounding environment. Based on direct observations and information in the field, from procuring seeds to planting cassava (cassava), the RPTRA management officer was carried out from the PPAPP Service, not also carried out by PKK members. Here it is clear that legally (based on Governor's Decree Number 349 of 2015 concerning the Implementation Team for the Development and Maintenance of the RPTRA), the role of the RPTRA manager must also be clarified so that its main tasks are focused and not extended to other work that is not their responsibility (overlapped).

\section{CONCLUSION}

The development of the RPTRA is a manifestation of the DKI Jakarta Government's service in serving the people's desire to get green open space in their daily life environment. RPTRA as an open space is feasible to be used and utilized for the public interest around the construction site. RPTRA, which presents Child-Friendly Integrated Public Space, is expected to be realized in reality and not just a concept. The idea and design must take into account: a) the Convention on the Rights of the Child (CRC) since 1990 with Presidential Decree No. 36 of 1990; b) RPTRA as a space for self-actualization of its users; c) RPTRA and human behaviour in public spaces; c) RPTRA Tidung Island as the culture of the archipelagic community, and d) RPTRA in the architectural design concept.

Tidung Island RPTRA in architectural approach - Several things that need to be considered as a reference in the development of RPTRA in the archipelago are: a) Access and affordability: site selection; b) Community involvement in RPTRA design; c) RPTRA which also basically pays attention to children with special needs; d) Maintaining Green Open Space compared to the existence of buildings in the RPTRA, the purpose is as a water catchment area; e) The construction of facilities in the RPTRA also prioritizes the problem of water catchment areas, especially in the construction of basketball, futsal and amphitheater fields that are full of concrete; f) The design of the RPTRA must take into account the weather conditions of the coastal areas or islands which tend to be hot/hot; g) There must be socialization to the community around the RPTRA on the character of the material and its use; h) RPTRA designer's understanding of zoning and facility classification between planting zones and play zones (children and adolescents/adults); i) It is necessary to pay close attention to the zoning arrangement of activities between toddlers (entertainment) and youth (sports), with a distance that is not too close together or touching; and j) Utilizing existing facilities outside the RPTRA as an attraction and expansion of RPTRA activities.

Tidung Island RPTRA in a legal approach - Several things that need to be considered as a reference in the development of RPTRA in the archipelago are: a) The legal aspects of establishing the RPTRA based on the ideal area; b) The concept of RPTRA as accommodating the idea of a child-friendly city based on existing regulations; c) The emergence of the problem of "the bond between RPTRA and the PKK Main Pro- 
gram" which seems to stand alone and run independently; and d) Legally, the role of the RPTRA manager must also be emphasized so that the main tasks are focused and not extended to other jobs that are not their responsibility (overlapped).

\section{REFERENCES}

Arlinkasari, Cushing, \& Miller. (2020). Play, Work, and Rest: The Developmental Affordances of Designated Child-Friendly Public Spaces in Jakarta, Indonesia. Children, Youth and Environments, 30(2), 119-119. Retrieved from https://dx.doi.org/10.7721/ chilyoutenvi.30.2.0119 10.7721/chilyoutenvi.30.2.0119

Arlinkasari, F. (2021). Qualitative Evaluation Of Child-Friendly Public Places In The Indonesian Urban Poverty Context (Doctoral Dissertation, Queensland University Of Technology).

Baslington, H. (2008). Travel Socialization: A Social Theory of Travel Mode Behavior. International Journal of Sustainable Transportation, 2(2), 91-114. Retrieved from https:// dx.doi.org/10.1080/15568310601187193 10.1080/15568310601187193

Brown, A. D., Kornberger, M., Clegg, S. R., \& Carter, C. (2010). 'Invisible walls' and 'silent hierarchies': A case study of power relations in an architecture firm. Human Relations, 63(4), 525-549. Retrieved from https://dx.doi.org/10.1177/0018726709339862 10 $.1177 / 0018726709339862$

Cao, L. (2010). In-Depth Behaviour Understanding And Use: The Behaviour Informatics Approach. Information Sciences., 180(17), 3067-3085.

Chan, L., Erlings, E., Mizunoya, S., \& Zaw, H. T. (2016). A City Fit For Children: Mapping And Analysis Of Child-Friendly Cities Initiatives. The Chinese University Of Hong Kong Faculty Of Law Research Paper., 2016-2051.

Decentralization And Local Governance In Developing Countries: A Comparative Perspective. (2006). In Bardhan, P. K., Mookherjee, \& D. (Eds.), . MIT Press.

Egaratri, C. L. (2017). Listening To The Neglected Whispers Of Jakarta: Understanding Poor Children's Outdoor Play.

Erul, E. (2018). Considering Residents' Behavioral Support For Tourism Development: A Theoretical Examination Of The Emotional Solidarity Theory And The Theory Of Planned Behavior (Doctoral Dissertation).

Faedlulloh, D., \& Prasetyani, R. (2017). The Implementation Model Of Deliberative Democracy Based Public Sphere In The Child-Friendly Integrated Public Sphere (RPTRA) In North Jakarta. Towards Open Government.

Faraz, M., Pratama, R., \&amp; Armeinita Octavia, E. H., \& Al. (2018). Evaluation Of Coastal Settlement Public Spaces: Study Of RPTRA Kamal Bahari, Kamal Muara Village", Slum Settlements And Illegal Buildings In Urban Areas: Embodiment Of Functions And Intersections Of Its Facilities (Yophie Septiady, Editor).

Fergie, G., Hunt, K., \& Hilton, S. (2016). Social media as a space for support: Young adults' perspectives on producing and consuming user-generated content about diabetes and mental health. Social Science \& Medicine, 170, 46-54. Retrieved from https://dx.doi .org/10.1016/j.socscimed.2016.10.006 10.1016/j.socscimed.2016.10.006

Ferrara, M., \& Friant, N. (2016). The application of a multi-methodology approach to a corpus of social representations. Quality \& Quantity, 50(3), 1253-1271. Retrieved from https://dx.doi.org/10.1007/s11135-015-0203-3 10.1007/s11135-015-0203-3

Goffman, E. (2017). Relations In Public: Micro Studies Of The Public Order. Routledge. 
Grusec, J. E. (2011). Socialization Processes in the Family: Social and Emotional Development. Annual Review of Psychology, 62(1), 243-269. Retrieved from https://dx.doi.org/ 10.1146/annurev.psych.121208.131650 10.1146/annurev.psych.121208.131650

Guest, G., Namey, E., \& Mitchell, M. (2013). In-Depth Interviews. Collecting Qualitative Data: A Field Manual For Applied Research [Online]., 113-171.

Haenfler, R., Johnson, B., \& Jones, E. (2012). Lifestyle Movements: Exploring the Intersection of Lifestyle and Social Movements. Social Movement Studies, 11(1), 1-20. Retrieved from https://dx.doi.org/10.1080/14742837.2012.640535 10.1080/14742837.2012 .640535

Håndlykken-Luz, Å. (2019). Polyhedron Of Powers, Displacements, Socio-Spatial Negotiations And Residents' Everyday Experiences In A “Pacified" Favela. ACME: An International Journal For Critical Geographies, 18(6), 1321-1346.

Hermawati, M., \& Muchbarak, A. (2020). Open Data Kit System Dan Smartphone Android As A South Jakarta RPTRA Data Collection Solution. Faktor Exacta(3), 13-13.

Jarvis, P. (2011). Paradoxes Of Learning: On Becoming An Individual In Society., 80.

Katz, M. M., \& Lyerly, S. B. (1963). Methods for Measuring Adjustment and Social Behavior in the Community: I. Rationale, Description, Discriminative Validity and Scale Development. Psychological Reports, 13(2), 503-535. Retrieved from https://dx.doi.org/ 10.2466/pr0.1963.13.2.503 10.2466/pr0.1963.13.2.503

Maslow, A. H. (2019). A Theory Of Human Motivation. General Press.

Pai, P., \& Tsai, H.-T. (2016). Reciprocity norms and information-sharing behavior in online consumption communities: An empirical investigation of antecedents and moderators. Information \& Management, 53(1), 38-52. Retrieved from https://dx.doi.org/10.1016/ j.im.2015.08.002 10.1016/j.im.2015.08.002

Partington, M., \& Cushion, C. (2013). An Investigation Of The Practice Activities And Coaching Behaviours Of Professional Top-Level Youth Soccer Coaches. Scandinavian Journal of Medicine \& Science In Sports, 23(3), 374-382.

Permanasari, E., Mochtar, S., \& Purisari, R. (2019). Political Representation In Urban Public Space In Jakarta Child-Friendly Public Space (Ruang Publik Terpadu Ramah Anak RPTRA). In International Journal of Built Environment and Sustainability (Vol. 6, pp. 3949). Penerbit UTM Press. Retrieved from https://dx.doi.org/10.11113/ijbes.v6.n2.351 10.11113/ijbes.v6.n2.351

Prakoso, S., \& Dewi, J. (2018). Child-friendly integrated public spaces (RPTRA): Uses and sense of attachment. IOP Conference Series: Earth and Environmental Science, 126, 012199-012199. Retrieved from https://dx.doi.org/10.1088/1755-1315/126/ 1/012199 10.1088/1755-1315/126/1/012199

Richards, R. (2007). Everyday Creativity: Our Hidden Potential.

Ritchie, J., Lewis, J., \& Nicholls, C. M. (2013). Qualitative Research Practises A Guide For Social Science Students And Researchers Sage. In Ormston \& R. (Eds.), .

Rustanto, A. E., \& Akhmad, J. (2021). RPTRA Activities Program In Services To The Community During The Covid-19 Pandemic. 1st Annual International Conference On Natural And Social Science Education, 2020, 97-102.

Stake, R. E. (2013). Multiple Case Study Analysis. Guilford Press.

Suraya, S., Fatmawati, R. A., Dindasari, D., Hutama, D. R., Christianti, I., \& Amanah, V. I. (2019). SOCIALIZATION OF HONESTY VALUES THROUGH STORY TELLING FOR CHILDREN IN EARLY AGE IN THE CHILD-FRIENDLY PUBLIC SPACE (RPTRA) JOGLO, WEST JAKARTA. ICCD, 2(1), 184-189. Retrieved from https://dx.doi.org/10.33068/iccd.vol2.iss1.162 10.33068/iccd.vol2.iss1.162 
Torabi, Z., \& Brahman, S. (2013). Practical Factors In Shaping The Identity Of Architecture. Middle-East Journal Of Scientific Research, 15(1), 106-113.

Tschersich, M., Kahl, C., Heim, S., Crane, S., Böttcher, K., Krontiris, I., \& Rannenberg, K. (2011). Towards privacy-enhanced mobile communities-Architecture, concepts and user trials. Journal of Systems and Software, 84(11), 1947-1960. Retrieved from https://dx.doi .org/10.1016/j.jss.2011.06.048 10.1016/j.jss.2011.06.048

Wang, L. J. (2013). Towards Cultural Citizenship? Cultural Rights And Cultural Policy In Taiwan. Citizenship Studies, 17(1), 92-110.

Yuniastuti, E., \& Hasibuan, H. S. (2019). Child-friendly green open space to enhance the education process for children. IOP Conference Series: Earth and Environmental Science, 243, 012161-012161. Retrieved from https://dx.doi.org/10.1088/1755-1315/243/ 1/012161 10.1088/1755-1315/243/1/012161 